\title{
Selection of a suitable multiresponse optimization technique for turning operation
}

\author{
I. Nayak ${ }^{\mathrm{a}^{*}}$ and J. Rana ${ }^{\mathrm{b}}$
}

${ }^{a}$ M. Tech Scholar (2nd yr), Department of Mechanical Engineering, Veer Surendra Sai University of Technology, Burla, Odisha, India ${ }^{b}$ Professor, Department of Mechanical Engineering, Veer Surendra Sai University of Technology, Burla, Odisha, India

\begin{tabular}{l}
\hline C H R O N I C L E \\
\hline Article history: \\
Received January 16, 2015 \\
Received in revised format: \\
June 12, 2015 \\
Accepted July 21, 2015 \\
Available online \\
July 21 2015 \\
\hline Keywords: \\
Multi response optimization \\
techniques \\
MRSN \\
WSN \\
GRA \\
VIKOR
\end{tabular}

\section{A B S T R A C T}

\begin{abstract}
The present work deals with the comparison of four multi response optimization methods, viz. multiple response signal-to-noise (MRSN) ratio, weighted signal-to-noise (WSN) ratio, Grey relational analysis (GRA), and VIKOR (VlseKriterijumska Optimizacija I Kompromisno Resenje in Serbian) methods taking a case study in turning mild steel specimen using HSS cutting tool. The various factors like cutting speed, feed rate, depth of cut and coolant flow rate are considered as the input process variables, while the material removal rate (MRR), surface roughness (SR) and specific energy consumption (SEC) are considered as various performance characteristics. One set of experimental data is analyzed using the standardized procedures. The optimization performances of these four methods are compared. The results show that MRSN ratio method proves to be the best optimization method. It is found that the feed rate has a highest impact on the overall performance as compared to other process parameters.
\end{abstract}

(c) 2016 Growing Science Ltd. All rights reserved.

\section{Introduction}

Improvement of productivity maintaining quality is the general goal of every organization. Automated and flexible manufacturing systems are therefore being employed for this purpose which are capable of achieving high accuracy at low processing time. Besides, process optimization is another technique employed to achieve this objective with the existing process or operation. Turning operation is the most common method used for machining and finishing of various parts. Nowadays, optimization of machining parameters is important while producing any product with desired quality. Optimization is the act of obtaining the best result under the given working conditions. It maximizes the desired benefits and minimizes the required input. The turning operation is controlled by tool geometry and process parameters. Several researchers have studied the influence of various process parameters such as cutting velocity, feed rate, depth of cut as well as the cutting fluid used on material removal rate (MRR) and other machining qualities like the surface roughness, circularity and dimensional deviations of the product in a turning operation (Kalpakjian \& Schmid, 2001). Generally MRR is directly related to the

* Corresponding author.

E-mail address: vijay_parashar@yahoo.com (V. Kumar) 
productivity of the process which ultimately leads to the growth or development of the organization. Similarly, improvement of surface finish is highly essential for improvement of working performance of different parts. Sahin and Motorcu (2008) employed the response surface methodology to minimize the surface roughness of AISI 1050 hardened steel bars using CBN and TiC cutting tools. Suhail et al. (2012) investigated the influence of cutting speed, feed rate and depth of cut on surface roughness using Grey Relational Analysis (GRA) technique. Gunay and Yucel (2013) used orthogonal array and analysis of variance (ANOVA) to evaluate the effect of cutting parameters on average surface roughness in turning high alloy white cast iron. Nian et al. (1999) took the significant cutting parameters (cutting speed, feed rate and depth of cut) into consideration and used multi response signal-to-noise (MRSN) ratio technique to study the effect of these parameters on tool life, cutting force and surface finish. Davim (2003) studied the influence of cutting conditions like cutting velocity, feed rate and cutting time on turning metal matrix composites using orthogonal array and analysis of variance to investigate the cutting characteristics of flank wear (VB), power required $\left(\mathrm{Pm}_{\mathrm{m}}\right)$ and surface roughness $\left(R_{a}\right)$. Sardinas et al. (2006) used a genetic algorithm based on multi objective optimization technique to optimize the cutting parameters in turning operation. However, very few researchers have studied the effect of cutting fluids (Kalpakjian \& Schmid, 2001; Baradie, 1996).

Effective application of cutting fluids can increase productivity, tool life, and dimensional accuracy and decrease the surface roughness and amount of power consumed. Jeyapaul et al. (2006) presented a case study to illustrate the potential of the integrated approach of Taguchi method and genetic algorithm for tackling multiple response optimization problems. Hascalik and Caydas (2008) employed the Taguchi's method to optimize the cutting parameters in turning commercial Ti-6Al-4V alloy using CNMG 120408-883 insert cutting tools. The results showed that the cutting speed and feed rate were the most influential factors on the surface roughness and tool life. Tong et al. (2007) proposed two case studies of plasma enhanced chemical vapor deposition and copper chemical mechanical polishing using VIKOR method, which was a compromise ranking approach used for multi-criteria decision making (MCDM), for optimizing multiple responses. Lin et al. (2009) proposed the Grey Relational Analysis technique to optimize the CNC turning operation parameters for SKD11 (JIS). The depth of cut was found to have most impact on the average roughness and the cutting speed was the most influential factor for the roughness and the roundness. Liao (2006) proposed a weighted principal component (WPC) analysis method, which took into account the possible correlations among various responses. Rao et al. (2013) adopted Taguchi's technique to study the influence of speed, feed and depth of cut on cutting force and surface roughness in turning AISI 1050 steel using ceramic tool. Shiau (1990) and Tai et al. (1992) determined the optimal parametric settings of different processes by optimizing the weighted signal-to-noise (WSN) ratio value.

Based on the exhaustive study of the past research works, it is observed that four multi response optimization techniques, e.g. MRSN ratio method (Nian et al., 1999), WSN ratio method (Shiau, 1990; Tai et al., 1992), GRA method (Lin et al., 2009), and VIKOR method (Tong et al., 2007) are quite simpler/robust in accordance to their computational procedures. There are some other multiresponse optimization techniques (Sahin \& Motorcu, 2008; Sardinas et al., 2006; Jeyapaul et al., 2006; Liao, 2006), which use complex mathematical/statistical tools and are, therefore, inconvenient to be used by the industrial personnel with little background in statistics and knowledge of software. Because of the computational simplicity, the above four multi response optimization techniques are chosen for the current study. The aim of this paper is to compare the above four optimization techniques using a set of experimental data from turning operation and to report for a suitable technique for this operation.

\section{Multiresponse optimization technique}

In the domain of advanced manufacturing technology, the only aim of all the engineers is to obtain the best process performance. Therefore, optimization has become the major quantitative tool in industrial decision making process. The main objective behind this is the minimization of production cost, 
maximization of production rate and maximization of profit rate. A number of researchers have proposed various techniques for optimizing single objective function as well as multi objective functions that reflect the machining performance. In single objective optimization technique, only one quality attribute is optimized which may lead to quality losses of other performance characteristics which may not be accepted by the customers. That is why, from engineering view point, multiresponse optimization techniques are more suitable. From an engineer's perspective, it is very important to know that out of various alternatives which method can lead to the best overall optimization performance for his/her process. Furthermore, a statistical analysis of variance (ANOVA) is performed to see which process parameters are statistically significant. Finally, a confirmatory experiment is conducted to verify the optimal process parameters.

\subsection{The MRSN, WSN, GRA, and VIKOR methods}

According to Taguchi (Kackar, 1985; Phadke, 1989) based methodology, the response variables are categorized into three types, e.g. the smaller the better, the larger the better and nominal the best. In this Taguchi's robust design of experimentation, let there are $m$ experimental trials, and in each trial, quality losses of a set of $p$ response variables are measured. The formulae for computing the quality loss $\left(L_{i j}\right)$ for $j$ th response corresponding to ith trial $(i=1,2, \ldots . m ; j=1,2, \ldots . . p)$ are different for different types of response variables and are given as follows:

For smaller the better, $L_{i j}=\frac{1}{n} \sum_{k=1}^{n} y_{i j k}^{2}$

For larger the better, $L_{i j}=\frac{1}{n} \sum_{k=1}^{n} \frac{1}{y_{i j k}^{2}}$,

For nominal the best, $L_{i j}=\frac{s_{i j}^{2}}{\bar{y}_{i j}^{2}}$,

where, $\bar{y}_{i j}=\frac{1}{n} \sum_{k=1}^{n} y_{i j k}, \quad S_{i j}^{2}=\frac{1}{n-1} \sum_{k=1}^{n}\left(y_{i j k}-\bar{y}_{i j}\right)^{2}$ and $n$ represent the number of repeated experiments, yijk represents the experimental value of the $j$ th response variable in ith trial at $k$ th replication, and $\mathrm{Lij}_{\mathrm{ij}}$ is the computed quality loss for $j$ th response in ith trial. For the analysis of all the four multi-response optimization methods, the following three common steps are followed:

Step 1: Conversion of the multiple responses into a single process performance index (PPI) for optimization.

Step 2: Determination of the significant factors and then, obtaining the optimal level combination.

Step 3: Validation of the optimal factor/level combination using confirmatory experiment.

\subsection{Determination of single process performance index (PPI) value}

\subsubsection{MRSN ratio method}

In MRSN method, the multi-response $\mathrm{S} / \mathrm{N}$ ratio is taken as the PPI, which can be obtained using the following steps:

Step 1: Calculation of scaled quality loss $\left(S_{i j}\right)$ for each response in each trial as follows,

$$
S_{i j}=L_{i j} / \bar{L}_{j} \text {, }
$$

where, $S_{i j}$ is the scaled quality loss for $j$ th response in $i$ th trial, $\bar{L}_{j}=\frac{1}{m} \sum_{i=1}^{m} L_{i j}$ is the average quality loss for the $j$ th response.

Step 2: Calculation of total loss function ( $\left.T L_{i}\right)$ for $i$ th trial using the following formula.

$$
T L_{i}=\sum_{i=1}^{m} w_{j} S_{i j},
$$


where, $w_{j}$ is the weight for the $j$ th response, chosen by the analyzer, and $\sum_{j=1}^{p} w_{j}=1$.

Step 3: Determination of multi-response S/N (MRSN) ratio for the ith trial, using the following formula.

$$
M R S N_{i}=-10 \log _{10}\left(T L_{i}\right) .
$$

\subsubsection{WSN method}

In this method, the WSN ratio is considered as the PPI value. The computational procedure for WSN ratio is as follows:

Step 1: The S/N ratio values $\left(\eta_{i j}\right)$ for all the responses for all the trials are first obtained as follows:

$$
\eta_{i j}=-10 \log _{10} L_{i j}
$$

Step 2: Computation of normalized $\mathrm{S} / \mathrm{N}$ ratio values for all the responses for all the trials as follows:

For larger the better: $Y_{i j}=\frac{\eta_{i j}-\eta_{j}^{\text {min }}}{\eta_{j}^{\text {max }}-\eta_{j}^{\text {min }}}$,

For smaller the better: $Y_{i j}=\frac{\eta_{j}^{\text {max }}-\eta_{i j}}{\eta_{j}^{\text {max }}-\eta_{j}^{\text {min }}}$,

where, $Y_{i j}$ is the normalized $\mathrm{S} / \mathrm{N}$ ratio or scaled $\mathrm{S} / \mathrm{N}$ ratio value for $j$ th $(j=1,2 \ldots \mathrm{p})$ response in $i$ th trial, $\eta_{j}^{\min }=\min \left\{\eta_{1 j}, \eta_{2 j} \ldots . . \eta_{\mathrm{m} j}\right\}$ and $\eta_{j}^{\max }=\max \left\{\eta_{1 j}, \eta_{2 j} \ldots . . \eta_{\mathrm{m} j}\right\}$. By using Eq. (8) and Eq. (9), the $\mathrm{S} / \mathrm{N}$ ratio values of a response variable are scaled into $(0,1)$ interval.

Step 3: Determination of the WSN value for the ith trial using the following equation:

$$
\operatorname{WSN}_{i}=\sum_{j=1}^{p} w_{j} Y_{i j}
$$

where, $w_{j}$ is the assigned weight for the $j$ th response, and $\sum_{j=1}^{p} w_{j}=1$.

\subsubsection{GRA method}

Grey relational grade is considered as the PPI, which can be obtained using the following steps:

Step 1: Computation of the $\mathrm{S} / \mathrm{N}$ ratio values for all the responses for all the trials, $\eta_{i j}$ using Eq. (7)

Step 2: Determination of the scaled $\mathrm{S} / \mathrm{N}$ ratio values for all the responses for all the trials, $Y_{i j}$ using Eq. (8) and Eq. (9) (as applicable).

Step 3: Computation of the grey relational coefficients, $\gamma_{i j}$ i.e.

$$
\gamma_{i j}=\frac{\Delta_{j}^{\min }+\xi \Delta_{j}^{\max }}{\Delta_{i j}+\xi \Delta_{j}^{\max }}
$$

where, $\Delta_{i j}=\left|1-Y_{i j}\right|, \Delta_{j}^{\min }=\min \left\{\Delta_{1 j}, \Delta_{2 j}, \ldots ., \Delta_{m j}\right\}, \Delta_{j}^{\max }=\max \left\{\Delta_{1 j}, \Delta_{2 j}, \ldots ., \Delta_{m j}\right\}$ and $\xi$ is the distinguishing coefficient $(\xi \in[0,1])$. The purpose of distinguishing coefficient is to expand or compress the range of the grey relational coefficient and usually, its value is taken as 0.5 .

Step 4: Calculation of the grey relational grade $\left(G R G_{i}\right)$ for $i$ th trial, i.e.

$$
G R G_{i}=\sum_{j=1}^{p} w_{j} \gamma_{i j},
$$

where, $w_{j}$ is the weight for the $j$ th response, and $\sum_{j=1}^{p} w_{j}=1$. 


\subsubsection{VIKOR method}

In the VIKOR method, the VIKOR index is taken as the PPI. The VIKOR index value for a trial can be computed using the following steps:

Step 1: Computation of the $\mathrm{S} / \mathrm{N}$ ratio values for all the responses for all the trials, $\eta_{i j}$ using Eq. (7)

Step 2: Determination of the scaled S/N ratio values for all the responses for all the trials, $Y_{i j}$ using Eq. (8)

Step 3: Determination of the ideal and negative ideal solutions.

The ideal solution $\left(A^{*}\right)$ and the negative ideal solution $\left(A^{-}\right)$are determined as follows:

$$
\begin{aligned}
A^{*} & =\max \left\{Y_{i j} \mid i=1,2, \ldots, m\right\}=\left\{Y_{1}^{*}, Y_{2}^{*}, \ldots . ., Y_{p}^{*}\right\} \\
A^{-} & =\min \left\{Y_{i j} \mid i=1,2, \ldots, m\right\}=\left\{Y_{1}^{-}, Y_{2}^{-}, \ldots . ., Y_{p}^{-}\right\}
\end{aligned}
$$

Step 4: Calculation of the utility and regret measure for each experimental trial, i.e.

$$
\begin{aligned}
S_{i} & =\sum_{j=1}^{n} w_{j}\left(Y_{j}^{*}-Y_{i j}\right) /\left(Y_{j}^{*}-Y_{j}^{-}\right), \\
R_{i} & =\max _{j}\left[w_{j}\left(Y_{j}^{*}-Y_{i j}\right) /\left(Y_{j}^{*}-Y_{j}^{-}\right)\right],
\end{aligned}
$$

where, $w_{j}$ is the weight for the $j$ th response, assigned by the analyzer, and $\sum_{j=1}^{p} w_{j}=1$.

Step 5: Calculation of the VIKOR index for the ith experimental trial, i.e.

$$
Q_{i}=v\left[\frac{S_{i}-S^{*}}{S^{-}-S^{*}}\right]+(1-v)\left[\frac{R_{i}-R^{*}}{R^{-}-R^{*}}\right] ; i=1,2, \ldots ., m
$$

where, $S^{*}=\min _{i} S_{i}, S^{-}=\max _{i} S_{i}, \mathrm{R}^{*}=\min R_{i}, R^{-}=\max _{i} R_{i}$ and $v$ is the weight of the maximum group utility and usually, it is set to 0.5 .

\section{Selection of a suitable multiresponse optimization technique using a case study}

In order to obtain the best multiresponse optimization technique out of the four given techniques, a case study on turning operation was performed by conducting a series of experiments. All the responses were well analyzed by the four different methods and the suitable parametric combination for the best technique was reported for the given turning operation.

\subsection{Experimental details}

\subsubsection{Workpiece Material, and Machine tool}

In this experiment, a round bar of mild steel (MS) having diameter of 32mm and length of 500mm was machined on a Turret Lathe. A high speed steel (HSS) cutting tool was used for this purpose. The chemical composition and mechanical properties of the workpiece are shown in Tab. 1 and Tab. 2,

\begin{tabular}{|c|c|c|c|c|c|c|}
\hline Element & $\mathrm{C}$ & $\mathrm{Si}$ & $\mathrm{Mn}$ & $S$ & $\mathrm{P}$ & $\mathrm{Fe}$ \\
\hline Percentage (\%) & 0.16 & 0.4 & 0.8 & 0.040 & 0.040 & 98 \\
\hline
\end{tabular}
respectively. The work material was cut, centered, and cleaned by removing a layer of material from the outside surface, prior to the actual machining.

\section{Table 1}

Chemical composition of workpiece material (MS) 
Table 2

Workpiece material properties

\begin{tabular}{ll}
\hline Workpiece material & Mild Steel \\
\hline Hardness $(\mathrm{HRB})$ & 68.5 \\
Melting Point $\left({ }^{\circ} \mathrm{C}\right)$ & $1350-1530$ \\
Density $\left(\mathrm{g} / \mathrm{mm}^{3}\right)$ & $7.85 \times 10^{-3}$ \\
Ultimate tensile strength $(\mathrm{MPa})$ & 1110 \\
Yield strength $(\mathrm{MPa})$ & 951 \\
Modulus of elasticity $(\mathrm{GPa})$ & 210 \\
\hline
\end{tabular}

\subsubsection{Selection of cutting parameters}

The variables that affect the performance of turning operation are identified based on experience and survey of past research works. Accordingly four machining parameters i.e. cutting speed, feed rate, depth of cut, and coolant flow rate, that affect the material removal rate, surface roughness, and specific energy consumption were selected. Each parameter has three levels, denoted by 1, 2, and 3 as low, medium, and high level respectively. Table 3 indicates the factors and their levels. The degrees of freedom for each parameter was obviously two. Experiments were conducted according to Taguchi's L9 orthogonal array, which is shown in Table 4.

Table 3

Machining parameters and their levels

\begin{tabular}{lllllll}
\hline Sl. No. & Parameter & Unit & Symbol & Level 1 & Level 2 & Level 3 \\
\hline 1 & Cutting speed & $\mathrm{m} / \mathrm{min}$ & $\mathrm{A}$ & 24.85 & 49.70 & 79.87 \\
2 & Feed rate & $\mathrm{mm} / \mathrm{rev}$ & $\mathrm{B}$ & 0.09 & 0.18 & 0.25 \\
3 & Depth of cut & $\mathrm{mm}$ & $\mathrm{C}$ & 0.25 & 0.35 & 0.5 \\
4 & Coolant flow rate & $\mathrm{ml} / \mathrm{sec}$ & $\mathrm{D}$ & 12 & 33 & 56 \\
\hline
\end{tabular}

\section{Table 4}

Layout of L9 orthogonal array

\begin{tabular}{lllll}
\hline Experiment number & A & B & C & D \\
\hline 1 & 1 & 1 & 1 & 1 \\
2 & 1 & 2 & 2 & 2 \\
3 & 1 & 3 & 3 & 3 \\
4 & 2 & 1 & 2 & 3 \\
5 & 2 & 2 & 3 & 1 \\
6 & 2 & 3 & 1 & 2 \\
7 & 3 & 1 & 3 & 2 \\
8 & 3 & 2 & 1 & 3 \\
9 & 3 & 3 & 2 & 1 \\
\hline
\end{tabular}

\subsubsection{Experimental procedure}

Fig. 1 represents the present experimental set up. A mild steel bar of $28 \mathrm{~mm}$ diameter, length $450 \mathrm{~mm}$ (machining length $50 \mathrm{~mm}$ ) was prepared and taken for conducting the experiment. The weight of the specimen was measured repeatedly each time before and after the experiment with the help of a high precision digital balance. Using different levels of the process parameters, nine experiments were conducted in the turret lathe. 


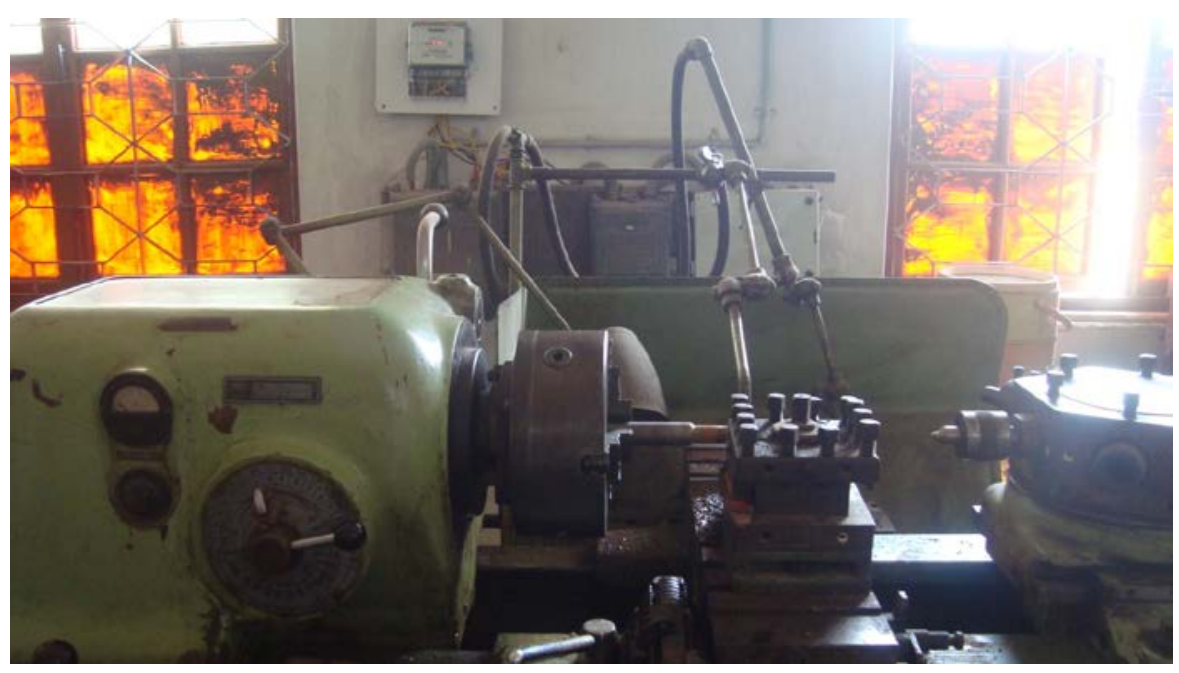

Fig. 1. Experimental set up

Machining time for each trial has been measured using a stop watch. In this experiment, the responses measured are material removal rate (MRR), surface roughness ( $\mathrm{Ra})$, and specific energy consumption (SEC). The MRR $\left(\mathrm{mm}^{3} / \mathrm{sec}\right)$ and SEC $\left(\mathrm{J} / \mathrm{mm}^{3}\right)$ were calculated using the Eq. 17 and Eq. 18, respectively. While the surface roughness $(\mathrm{Ra})$ was measured using a $2 \mathrm{D}$ portable surface profilometer (Make: Taylor Hobson, Model: Talysurf, Surtronic 3+) as shown in Fig. 2. The cut-off length and assessment length were taken to be $0.8 \mathrm{~mm}$ and $4 \mathrm{~mm}$, respectively.

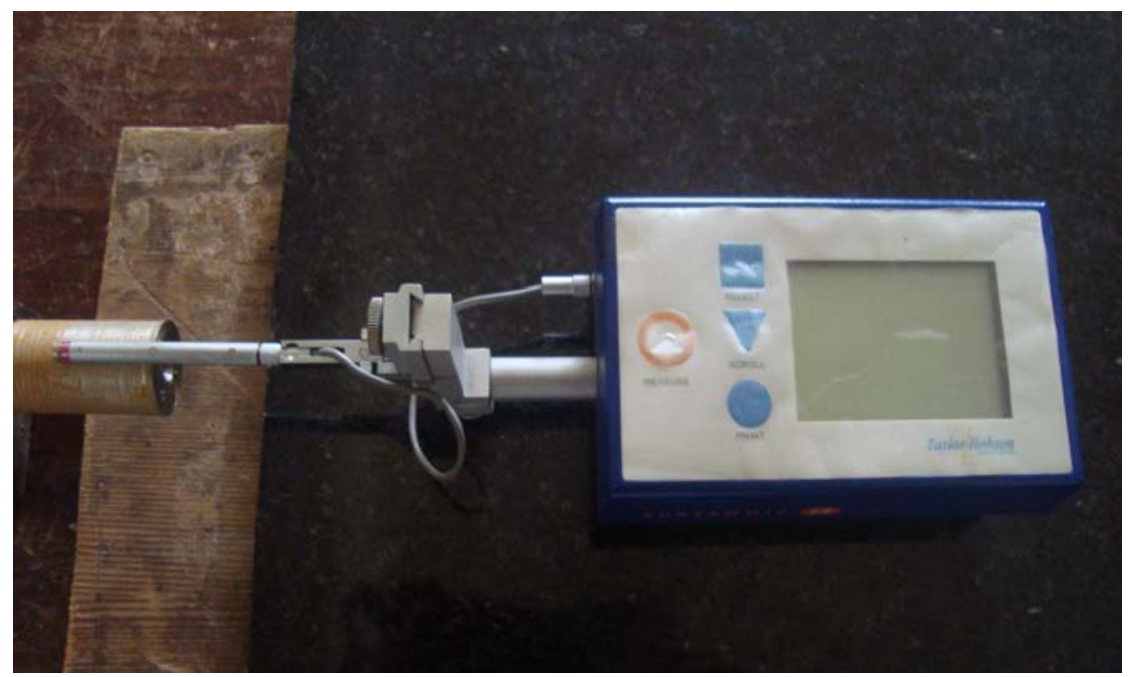

Fig. 2. Talysurf, Surtronic 3+

Material removal rate,

$$
M R R=\frac{w_{i}-w_{f}}{\rho t} \mathrm{~mm}^{3} / \mathrm{sec},
$$

where, $w_{i}$ is the weight of the specimen before machining, $w_{f}$ is the weight of the specimen after machining measured on an digital balance, $\rho$ is the density of the work material i.e. $7.85 \times 10^{-3} \mathrm{~g} / \mathrm{mm}^{3}$ ), and $t$ is the machining time.

Specific energy consumption, $S E C=\frac{P}{M R R \times t} \mathrm{~J} / \mathrm{mm}^{3}$, 
where, $P$ is the energy meter reading taken during the experiment, and $t$ is the machining time. The experimental results are presented in Table 5.

Table 5

Experimental results

\begin{tabular}{llllllllll}
\hline Expt. No. & $\begin{array}{l}\text { Speed } \\
(\mathrm{m} / \mathrm{min})\end{array}$ & $\begin{array}{l}\text { Feed rate } \\
(\mathrm{mm} / \mathrm{rev})\end{array}$ & $\begin{array}{l}\text { Depth of } \\
\text { cut }(\mathrm{mm})\end{array}$ & $\begin{array}{l}\text { Coolant } \\
\text { flow rate } \\
(\mathrm{ml} / \mathrm{sec})\end{array}$ & $\begin{array}{l}\mathrm{MRR} \\
\left(\mathrm{mm}^{3} / \mathrm{sec}\right)\end{array}$ & $\mathrm{R}_{\mathrm{a} 1}$ & $\mathrm{R}_{\mathrm{a} 2}$ & $\mathrm{R}_{\mathrm{a} 3}$ & $\begin{array}{l}\text { SEC } \\
\left(\mathrm{J} / \mathrm{mm}^{3}\right)\end{array}$ \\
\hline 1 & 24.85 & 0.09 & 0.25 & 12 & 5.587 & 6.44 & 5.88 & 6.52 & 282.611 \\
2 & 24.85 & 0.18 & 0.35 & 33 & 25.478 & 7.08 & 6.96 & 6.62 & 47.099 \\
3 & 24.85 & 0.25 & 0.5 & 56 & 43.312 & 7.96 & 7.92 & 7.54 & 33.247 \\
4 & 49.70 & 0.09 & 0.35 & 56 & 32.970 & 6.72 & 6.26 & 6.00 & 80.742 \\
5 & 49.70 & 0.18 & 0.5 & 12 & 75.406 & 5.62 & 5.06 & 5.48 & 17.662 \\
6 & 49.70 & 0.25 & 0.25 & 33 & 63.496 & 6.20 & 5.88 & 6.30 & 35.325 \\
7 & 79.87 & 0.09 & 0.5 & 33 & 11.560 & 3.34 & 3.54 & 3.24 & 188.407 \\
8 & 79.87 & 0.18 & 0.25 & 56 & 63.405 & 4.28 & 4.16 & 3.96 & 35.225 \\
9 & 79.87 & 0.25 & 0.35 & 12 & 34.723 & 6.40 & 5.86 & 6.14 & 188.402 \\
\hline
\end{tabular}

\subsection{Results and Discussion}

In this section, the experimental data given in Table 5 are analyzed by the four different multi response optimization techniques which are described earlier. An analysis of variance (ANOVA) is applied to estimate the effect of various machining parameters on optimization of multiple performance characteristics of the turning process. Based on the results of process performance index (PPI) values and ANOVA results, optimal machining parameters with the consideration of multiple performance characteristics have been obtained and verified.

\subsubsection{Analysis of the experimental data}

In this present study, the larger the better, and the smaller the better principles are considered to maximize the material removal rate (MRR) and to minimize the surface roughness ( $\mathrm{R} a$ ), and specific energy consumption (SEC), respectively. The first step in data analysis is to calculate the quality losses of a set of $p$ response variables. The loss function for MRR was calculated using Eq. (2). Similarly Eq. 1 was applied to calculate the loss function for surface roughness and specific energy consumption. In this study, all the responses are given equal priority. The PPI values for the four multi response optimization techniques obtained by using the standard formulas stated earlier are given in Table 6 .

\section{Table 6}

PPI values for MRSN, WSN, GRA, and VIKOR method

\begin{tabular}{lllll}
\hline Expt. No. & $\begin{array}{l}\text { PPI value } \\
\text { MRSN }\end{array}$ & WSN & GRG & VIKOR index \\
\hline 1 & -6.0398 & 0.5805 & 0.6641 & 0.5000 \\
2 & 2.2944 & 0.5958 & 0.5838 & 0.6569 \\
3 & 2.0294 & 0.6717 & 0.6981 & 0.7979 \\
4 & 2.5383 & 0.6602 & 0.6012 & 0.5913 \\
5 & 5.3835 & 0.5195 & 0.6214 & 0.7056 \\
6 & 4.0782 & 0.6317 & 0.6391 & 0.7002 \\
7 & -1.0322 & 0.3777 & 0.5055 & 0.6698 \\
9 & 6.9940 & 0.4751 & 0.5599 & 0.2440 \\
\hline
\end{tabular}

Since the experimental design is orthogonal, it is possible to separate out the effect of each machining parameter at different factor levels. The calculated mean MRSN ratio, WSN ratio, GRG, and VIKOR index of each machining parameter at different factor levels are presented in Tables 7. The optimal factor/level combination can be easily determined by examining the level averages of the various factors. Larger values of MRSN, WSN, and GRG (boldfaced in the respective table) signify better 
quality. However, in the VIKOR method a higher value of VIKOR index is not desirable (Tong et al., 2007). Because, a smaller value of VIKOR index requires less compromise for ensuring small variation in $\mathrm{S} / \mathrm{N}$ ratios among the responses along with a large overall $\mathrm{S} / \mathrm{N}$ ratio, which is preferable.

The optimal combination for the factors A, B, C and D with respect to MRSN, WSN, GRG, and VIKOR index can be set as $A_{2} B_{2} C_{3} D_{3}, A_{1} B_{3} C_{2} D_{1}, A_{1} B_{3} C_{2} D_{1}$, and $A_{3} B_{2} C_{1} D_{3}$ respectively. It may be noted here that both the WSN ratio and GRG methods lead to the same optimal condition, whereas, the optimal parameter combination obtained for the VIKOR method is $\mathrm{A}_{3} \mathrm{~B}_{2} \mathrm{C}_{1} \mathrm{D}_{1}$.

\section{Table 7}

Level averages of the factors on different PPI values

\begin{tabular}{lllllllllllll}
\hline \multirow{2}{*}{ Factors } & MRSN & \multicolumn{4}{c}{ LSN } & \multicolumn{4}{c}{ GRG } & \multicolumn{4}{c}{ VIKOR index } \\
& Level & Level & Level & Level & Level & Level & Level & Level & Level & Level & Level & Level \\
\hline $\mathrm{A}$ & - & $\mathbf{4 . 0 0 0}$ & 1.9029 & $\mathbf{0 . 6 1 6 0}$ & 0.6038 & 0.5363 & $\mathbf{0 . 6 4 8 7}$ & 0.6206 & 0.5813 & 0.6516 & 0.6657 & $\mathbf{0 . 5 0 5 7}$ \\
$\mathrm{B}$ & - & $\mathbf{4 . 8 9 0 6}$ & 1.9515 & 0.5395 & 0.5301 & $\mathbf{0 . 6 8 6 5}$ & 0.5903 & 0.5884 & $\mathbf{0 . 6 7 1 9}$ & 0.5870 & $\mathbf{0 . 5 3 5 5}$ & 0.7005 \\
$\mathrm{C}$ & 1.6775 & 1.5266 & $\mathbf{2 . 1 2 6 9}$ & 0.5624 & $\mathbf{0 . 6 7 0 7}$ & 0.5230 & 0.6210 & $\mathbf{0 . 6 2 1 2}$ & 0.6083 & $\mathbf{0 . 4 8 1 4}$ & 0.6172 & 0.7244 \\
$\mathrm{D}$ & - & 1.7801 & $\mathbf{3 . 8 5 3 9}$ & $\mathbf{0 . 6 1 8 7}$ & 0.5351 & 0.6023 & $\mathbf{0 . 6 5 4 7}$ & 0.5761 & 0.6197 & $\mathbf{0 . 6 0 3 0}$ & 0.6756 & 0.6444 \\
\hline
\end{tabular}

\subsubsection{Analysis of variance}

After calculating the mean PPI value for each experiment, the next step in the data analysis is to estimate the effect of each machining parameter on the responses and to perform the analysis of variance (ANOVA). ANOVA is a well established method (Montgomery, 2001) that can identify the significant/influencing factors most efficiently in relation to the error variance. In ANOVA analysis, to identify the significant effect of each process parameter on the performance characteristics, the F-test is conducted. The $F$ value for a factor is obtained as the ratio of mean square $\left(\mathrm{SS}_{\mathrm{m}}\right)$ due to the factor and error. When $\mathrm{SS}_{\mathrm{m}}$ is equal to the sum of squared deviation (SS) divided by the number of degrees of freedom associated with the process parameter. The computed $F$ value is very useful in understanding the relative influence of different factors on a process parameter. According to Taguchi (Phadke, 1989), a value of $F$ ratio greater than 2 means the factor effect is not quite small, and larger than 4 means the factor effect is quite large, whereas a value of $F$ ratio less than 1 means the factor effect is smaller than the error. Figs. (3-6) represent the various factor effects on the PPI values, e.g., MRSN ratio, WSN ratio, GRG, and VIKOR index, respectively.

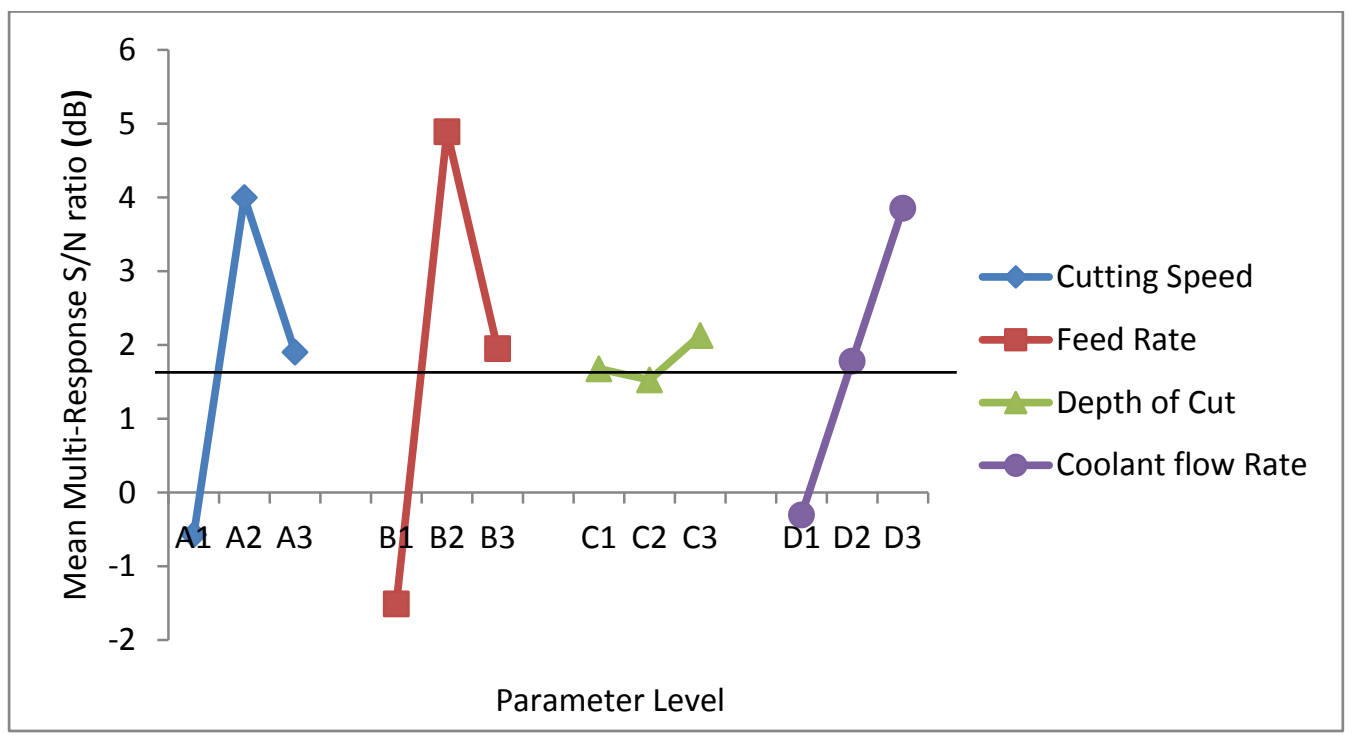

Fig. 3. Response graph of MRSN ratio 


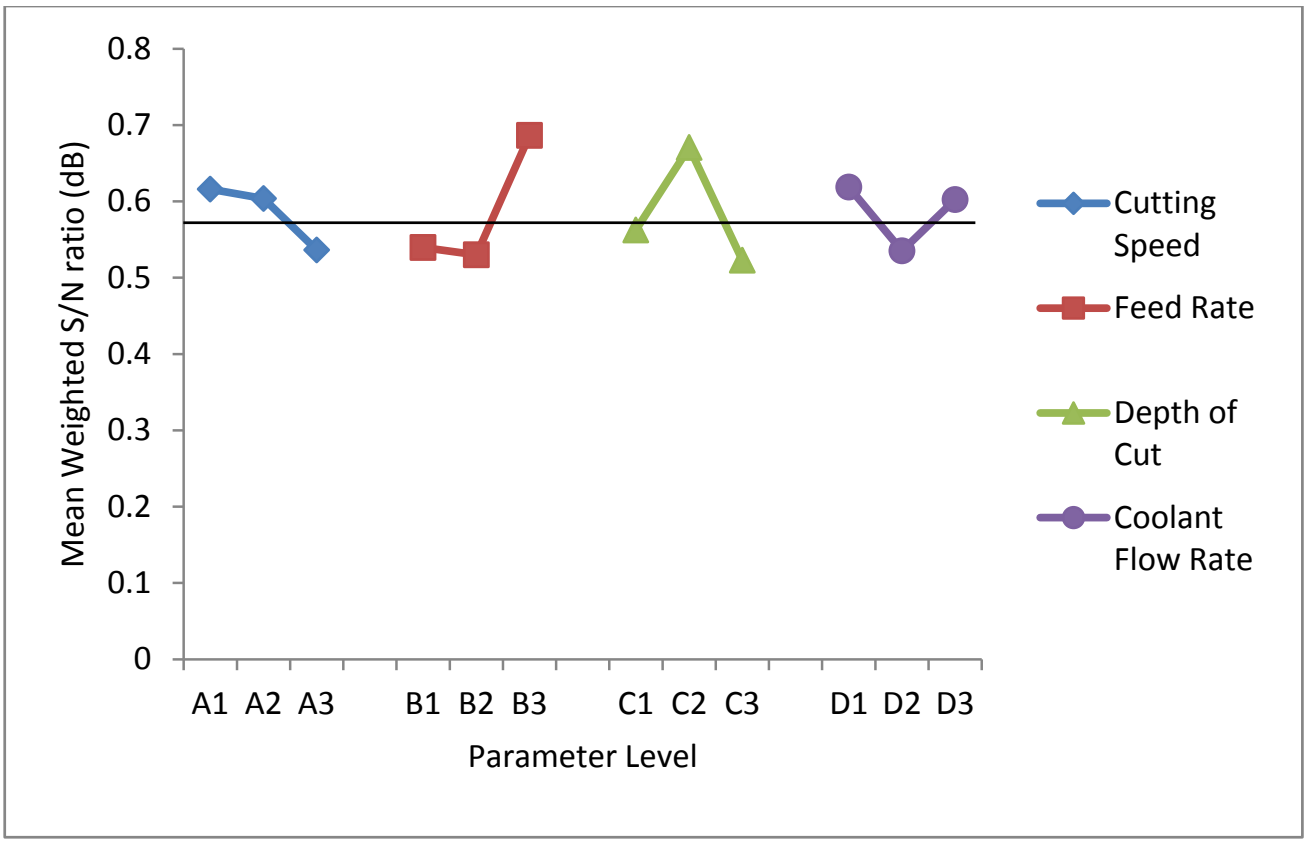

Fig. 4. Response graph of WSN ratio

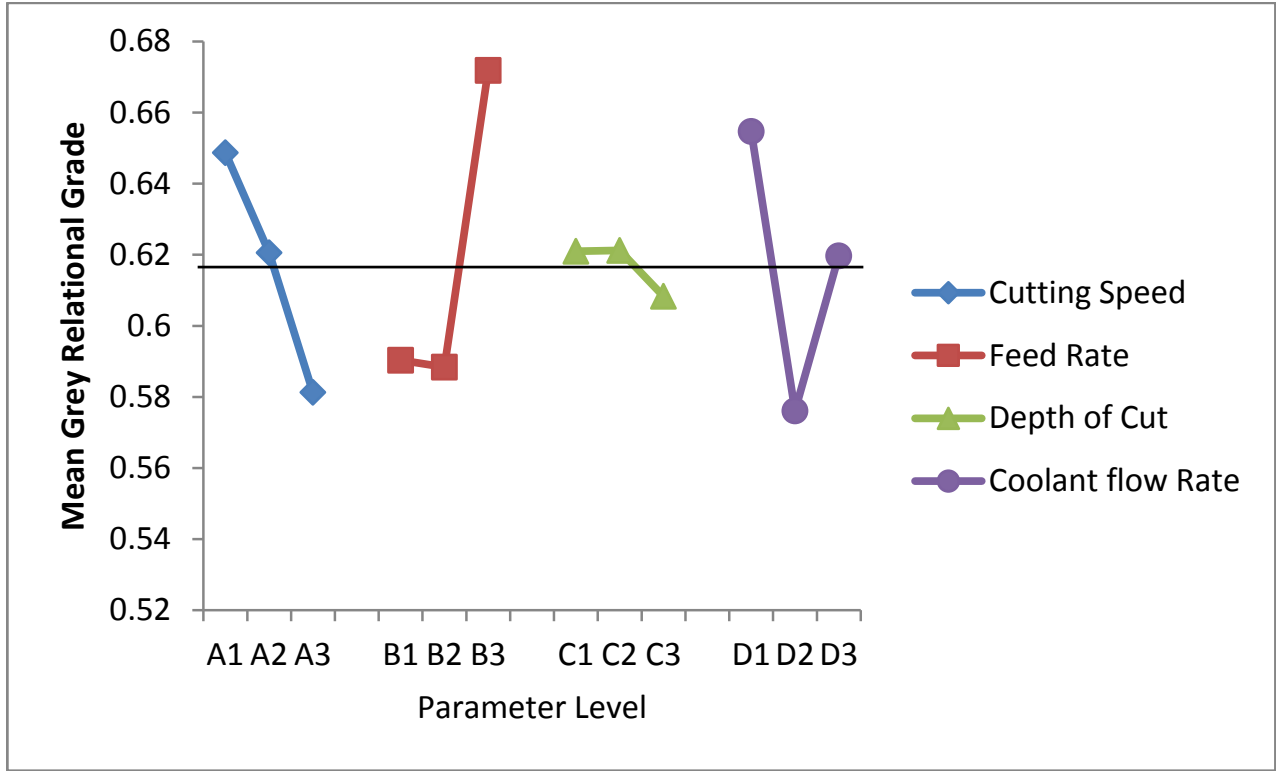

Fig. 5. Response graph of grey relational grade (GRG)

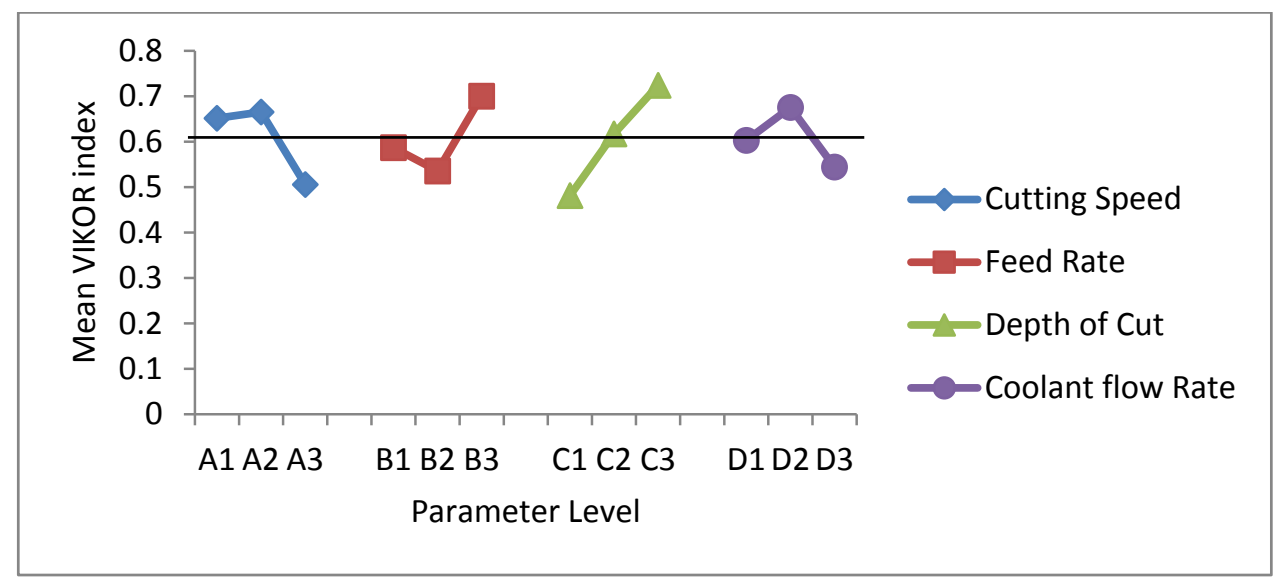

Fig. 6. Response graph of VIKOR index 
The analysis of variance is carried out separately for all the four types of PPIs. Table 8 shows the ANOVA results for MRSN, WSN, and Table 9 shows the ANOVA results for GRG, and VIKOR index.

\section{Table 8}

Results of ANOVA for MRSN, and WSN

\begin{tabular}{|c|c|c|c|c|c|c|c|c|c|c|}
\hline \multirow{2}{*}{$\begin{array}{l}\text { Sources } \\
\text { of } \\
\text { variance }\end{array}$} & \multicolumn{5}{|l|}{ MRSN } & \multicolumn{5}{|l|}{ WSN } \\
\hline & SS & $\mathrm{DF}$ & $\mathrm{SS}_{\mathrm{m}}$ & $F$ & P (\%) & SS & $\mathrm{DF}$ & $\mathrm{SS}_{\mathrm{m}}$ & $F$ & P (\%) \\
\hline A & 31.4261 & 2 & 15.7130 & 53.7196 & 26.29 & 0.0111 & 2 & 0.0055 & 1 & 10.59 \\
\hline B & 61.6116 & 2 & 30.8058 & 105.3190 & 51.54 & 0.0461 & 2 & 0.0230 & 4.1818 & 44.32 \\
\hline C & 0.5851 & 2 & 0.2925 & 1 & 0.49 & 0.0351 & 2 & 0.0175 & 3.1818 & 33.72 \\
\hline D & 25.9210 & 2 & 12.9605 & 44.3094 & 21.68 & 0.0118 & 2 & 0.0059 & 1.0727 & 11.37 \\
\hline Error & $\mathrm{C}$ & - & - & - & - & A & - & - & - & - \\
\hline Total & 119.5438 & 8 & - & - & 100 & 0.1041 & 8 & - & - & 100 \\
\hline
\end{tabular}

Table 9

Results of ANOVA for GRG, and VIKOR

\begin{tabular}{|c|c|c|c|c|c|c|c|c|c|c|}
\hline \multirow{2}{*}{$\begin{array}{l}\text { Sources } \\
\text { of } \\
\text { variance }\end{array}$} & \multicolumn{5}{|l|}{ GRG } & \multicolumn{5}{|c|}{ VIKOR } \\
\hline & SS & DF & $\mathrm{SS}_{\mathrm{m}}$ & $F$ & P (\%) & SS & $\mathrm{DF}$ & $\mathrm{SS}_{\mathrm{m}}$ & $F$ & $\mathrm{P}(\%)$ \\
\hline A & 0.0069 & 2 & 0.0034 & 22.6667 & 22.59 & 0.0471 & 2 & 0.0235 & 1.8217 & 22.99 \\
\hline B & 0.0136 & 2 & 0.0068 & 45.3333 & 45.18 & 0.0427 & 2 & 0.0213 & 1.6512 & 20.84 \\
\hline C & 0.0003 & 2 & 0.00015 & 1 & 1.00 & 0.0890 & 2 & 0.0445 & 3.4496 & 43.54 \\
\hline D & 0.0093 & 2 & 0.0047 & 31.3333 & 31.23 & 0.0259 & 2 & 0.0129 & 1 & 12.63 \\
\hline Error & $\mathrm{C}$ & - & - & - & - & $\mathrm{D}$ & - & - & - & - \\
\hline Total & 0.0301 & 8 & - & - & 100 & 0.2047 & 8 & - & - & 100 \\
\hline
\end{tabular}

It is observed from Tab. 8 and 9 that factor B is the most influencing one with respect to MRSN, WSN, and GRG values, and, factor $\mathrm{C}$ is significant with respect to the VIKOR index value only.

\subsubsection{Verification of the experiments}

After selecting the optimal level of the process parameters, the final step is to predict and verify the improvement of the performance characteristics with the selected optimal process parameters. The predicted optimal values of the $\mathrm{S} / \mathrm{N}$ ratios $\left(\eta_{\text {opt }}\right)$ using the optimum level of process parameters can be calculated as:

$\eta_{o p t}=\eta_{m}+\sum_{i=1}^{q}\left(\overline{\eta_{l}}-\eta_{m}\right)$

where, $\eta_{m}$ is the grand mean of PPI values, $\overline{\eta_{l}}$ is the mean PPI value at the optimum level, and $q$ is the number of the machining parameters that significantly affect the multiple response characteristics. For the better understanding of the correlation between the input parameters and output responses, the prediction models for MRR, SR and SEC has been obtained using multiple regression analysis. The input parameters are cutting speed $\left(\mathrm{V}_{\mathrm{c}}\right)$, feed rate (f), depth of cut (d) and coolant flow rate (Q) respectively. The following equations are obtained using the regression analysis:

$M R R=-4.8+0.182 V_{c}+170 f+3.8 d+0.188 Q$ 
$S R=7.03-0.0424 V_{c}+5.45 f+0.05 d+0.0039 Q$

$S E C=315+0.40 V_{c}-575 f-153 d-2.56 Q$

Table 10,11,12, and 13 show the comparison of estimated PPI value with the actual PPI value obtained in the confirmatory experiments using the optimal cutting parameters. Based on the experimental confirmation, the material removal rate is increased by $7.52 \%$, the surface roughness is decreased by $10.53 \%$, and the specific energy consumption is increased by $9.38 \%$ for the MRSN ratio method. Similarly, for the WSN ratio method and the GRA method, MRR is increased by $13.01 \%$, the Ra value is decreased by $10.94 \%$, and the SEC is increased by $10.99 \%$. In case of VIKOR method, MRR value is increased by $9.2 \%$, the $R_{a}$ value is increased by $9.54 \%$ and the SEC value is increased by $12.85 \%$. It is evident that, out of the four prospective methods, good improvement of MRR, SR, and SEC has been obtained by the MRSN ratio method. As well as, good approximation also exists between the predicted value (9.5404) and the experimental value (9.9524) of the mean MRSN ratio.

Table 10

Results of the confirmatory experiment for MRSN ratio method

\begin{tabular}{lccc} 
& \multirow{2}{*}{ Initial factor setting } & \multicolumn{2}{c}{ Optimal cutting parameters } \\
\cline { 3 - 4 } & $\mathrm{A}_{1} \mathrm{~B}_{1} \mathrm{C}_{1} \mathrm{D}_{1}$ & Prediction & Experiment \\
\hline Level & 5.587 & $\mathrm{~A}_{2} \mathrm{~B}_{2} \mathrm{C}_{3} \mathrm{D}_{3}$ & $\mathrm{~A}_{2} \mathrm{~B}_{2} \mathrm{C}_{3} \mathrm{D}_{3}$ \\
MRR $\left(\mathrm{mm}^{3} / \mathrm{sec}\right)$ & 6.28 & 47.273 & 50.828 \\
SR $(\mu \mathrm{m})$ & 282.611 & 6.147 & 5.5 \\
SEC $\left(\mathrm{J} / \mathrm{mm}^{3}\right)$ & -6.0398 & 11.52 & 12.601 \\
MRSN ratio & -6.5404 & 9.9524 \\
\hline Improvement in MRSN ratio $=15.9922$ & & 9.5404 \\
\hline
\end{tabular}

\section{Table 11}

Results of the confirmatory experiment for WSN ratio method

\begin{tabular}{llcc} 
& \multirow{2}{*}{ Initial factor setting } & \multicolumn{2}{c}{ Optimal cutting parameters } \\
\cline { 2 - 4 } & & \multicolumn{2}{c}{ Prediction } \\
Level & $\mathrm{A}_{1} \mathrm{~B}_{1} \mathrm{C}_{1} \mathrm{D}_{1}$ & $\mathrm{~A}_{1} \mathrm{~B}_{3} \mathrm{C}_{2} \mathrm{D}_{1}$ & $\mathrm{~A}_{1} \mathrm{~B}_{3} \mathrm{C}_{2} \mathrm{D}_{1}$ \\
$\mathrm{MRR}\left(\mathrm{mm}^{3} / \mathrm{sec}\right)$ & 5.587 & 45.8087 & 51.764 \\
$\mathrm{SR}(\mu \mathrm{m})$ & 6.28 & 7.40 & 6.59 \\
$\mathrm{SEC}\left(\mathrm{J} / \mathrm{mm}^{3}\right)$ & 282.611 & 96.92 & 107.58 \\
WSN ratio & 0.5805 & 0.8357 & 0.7687 \\
\hline Improvement in WSN ratio $=0.1882$ & & \\
\hline
\end{tabular}

\section{Table 12}

Results of the confirmatory experiment for GRA method

\begin{tabular}{llcc}
\hline & \multirow{2}{*}{ Initial factor setting } & \multicolumn{2}{c}{ Optimal cutting parameters } \\
Level & $\mathrm{A}_{1} \mathrm{~B}_{1} \mathrm{C}_{1} \mathrm{D}_{1}$ & Prediction & Experiment \\
MRR $\left(\mathrm{mm}^{3} / \mathrm{sec}\right)$ & 5.587 & $\mathrm{~A}_{1} \mathrm{~B}_{3} \mathrm{C}_{2} \mathrm{D}_{1}$ & $\mathrm{~A}_{1} \mathrm{~B}_{3} \mathrm{C}_{2} \mathrm{D}_{1}$ \\
$\mathrm{SR}(\mu \mathrm{m})$ & 6.28 & 45.8087 & 51.764 \\
$\mathrm{SEC}\left(\mathrm{J} / \mathrm{mm}^{3}\right)$ & 282.611 & 7.40 & 6.59 \\
GRG & 0.6641 & 96.92 & 107.58 \\
\hline Improvement in GRG $=0.0287$ & 0.7458 & 0.6928 \\
\hline
\end{tabular}

\section{Table 13}

Results of the confirmatory experiment for VIKOR method

\begin{tabular}{llcc}
\hline & \multirow{2}{*}{ Initial factor setting } & \multicolumn{2}{c}{ Optimal cutting parameters } \\
\cline { 3 - 4 } & $\mathrm{A}_{1} \mathrm{~B}_{1} \mathrm{C}_{1} \mathrm{D}_{1}$ & Prediction & Experiment \\
\hline Level & 5.587 & $\mathrm{~A}_{3} \mathrm{~B}_{2} \mathrm{C}_{1} \mathrm{D}_{1}$ & $\mathrm{~A}_{3} \mathrm{~B}_{2} \mathrm{C}_{1} \mathrm{D}_{1}$ \\
MRR $\left(\mathrm{mm}^{3} / \mathrm{sec}\right)$ & 43.542 & 47.548 \\
$\mathrm{SR}(\mu \mathrm{m})$ & 6.28 & 4.683 & 5.13 \\
SEC $\left(\mathrm{J} / \mathrm{mm}^{3}\right)$ & 282.611 & 174.478 & 196.905 \\
VIKOR index & 0.5000 & 0.3026 & 0.6867 \\
\hline Improvement in VIKOR index $=0.1867$ & & \\
\hline
\end{tabular}




\section{Conclusion}

In the present paper, four prospective multi objective optimization techniques, e.g., MRSN ratio, WSN ratio, GRA, and VIKOR methods, have been used to obtain the optimal turning parameters that lead to maximum material removal rate, minimum surface roughness and specific energy consumption value. The results obtained from the analysis are summarized as follows:

1. From the confirmation test, it is found that no method can give better overall quality than that resulted under the optimal condition derived using the MRSN ratio method as the percentage error is very low. Since, the maximization of material removal rate, and minimization of surface roughness and specific energy consumption are simultaneously considered, a cutting speed of $49.70 \mathrm{~m} / \mathrm{min}$, feed rate of $0.18 \mathrm{~mm} / \mathrm{rev}$, depth of cut of $0.5 \mathrm{~mm}$, and the coolant flow rate of $56 \mathrm{ml} / \mathrm{sec}$, are recommended as the optimal cutting parameters for the turning operation.

2. From the ANOVA analysis, the importance of the controllable cutting parameters is found to be in the sequence of, feed rate, cutting speed, coolant flow rate, and depth of cut. The feed rate is identified as the most significant controlled factor as it has the maximum percentage of contribution (51.54\%) towards the turning operation. On the other hand depth of cut has the least effect on the turning operation.

\section{Acknowledgments}

The authors wish to thank the Department of Mechanical Engineering in Veer Surendra Sai University of Technology for their support and co-operation for performing the experimental work.

\section{References}

Baradie EI, M.A. (1996). Cutting fluids: part I characterization. Journal of Material Processing Technology, 56, 786-797.

Davim, J. P. (2003). Design of optimization of cutting parameters for turning metal matrix composites based on the orthogonal arrays. Journal of Materials Processing Technology, 132(1), 340-344.

Gauri, S. K., \& Chakraborty, S. (2009). Optimization of multiple responses for WEDM processes using weighted principal components. The International Journal of Advanced Manufacturing Technology, 40(11-12), 1102-1110.

Gunay, M., \& Yucel, E. (2013). Application of Taguchi method for determining optimum surface roughness in turning of high-alloy white cast iron. Measurement, 46(2), 913-919.

Hascalık, A., \& Caydas, U. (2008). Optimization of turning parameters for surface roughness and tool life based on the Taguchi method. The International Journal of Advanced Manufacturing Technology, 38(9-10), 896-903.

Jeyapaul, R., Shahabudeen, P., \& Krishnaiah, K. (2006). Simultaneous optimization of multi-response problems in the Taguchi method using genetic algorithm. The International Journal of Advanced Manufacturing Technology, 30(9-10), 870-878.

Kackar, R.N. (1985). Off-line quality control, parameter design and the Taguchi method. Journal of Quality Technology, 17, 176-188.

Kalpakjian, S., \& Schmid, S.R. (2001). Manufacturing Engineering and Technology, International, Fourth ed. Prentice Hall Co., New Jersey, 536-681.

Liao, H. C. (2006). Multi-response optimization using weighted principal component. The International Journal of Advanced Manufacturing Technology, 27(7-8), 720-725.

Montgomery DC. (2001). Design and Analysis of Experiments. $5^{\text {th }}$ ed., Wiley, Singapore.

Nian, C. Y., Yang, W. H., \& Tarng, Y. S. (1999). Optimization of turning operations with multiple performance characteristics. Journal of Materials Processing Technology, 95(1), 90-96.

Phadke, M. S. (1989). Quality Engineering Using Robust Design, PTR Prentice-Hall. Inc., Englewood Cliffs, NJ. 
Rao, C. J., Rao, D. N., \& Srihari, P. (2013). Influence of cutting parameters on cutting force and surface finish in turning operation. Procedia Engineering, 64, 1405-1415.

Sahin, Y., \& Motorcu, A. R. (2008). Surface roughness model in machining hardened steel with cubic boron nitride cutting tool. International Journal of Refractory Metals and Hard Materials, 26(2), 84-90.

Sardinas, R. Q., Santana, M. R., \& Brindis, E. A. (2006). Genetic algorithm-based multi-objective optimization of cutting parameters in turning processes. Engineering Applications of Artificial Intelligence, 19(2), 127-133.

Shiau GH. (1990). A study of the sintering properties of iron ores using the Taguchi's parameter design. Journal of Chinese Statistical Association, 28, 253-275.

Suhail, A. H., Ismail, N., Wong, S. V., \& Jalil, N. A. (2012). Surface roughness identification using the grey relational analysis with multiple performance characteristics in turning operations. Arabian Journal for Science and Engineering, 37(4), 1111-1117.

Tai, C. Y., Chen, T. S., \& Wu, M. C. (1992). An enhanced Taguchi method for optimizing SMT processes. Journal of Electronics Manufacturing, 2(03), 91-100.

Tong, L. I., Chen, C. C., \& Wang, C. H. (2007). Optimization of multi-response processes using the VIKOR method. The International Journal of Advanced Manufacturing Technology, 31(11-12), 1049-1057.

Tzeng, C. J., Lin, Y. H., Yang, Y. K., \& Jeng, M. C. (2009). Optimization of turning operations with multiple performance characteristics using the Taguchi method and Grey relational analysis. Journal of Materials Processing Technology, 209(6), 2753-2759. 